\title{
Dietary fat increases solid tumor growth and metastasis of 4T1 murine mammary carcinoma cells and mortality in obesity-resistant BALB/c mice
}

\author{
Eun Ji Kim², Mi-Ran Choi ${ }^{2}$, Heesook Park', Minhee Kim, Ji Eun Hong ${ }^{2}$, Jae-Yong Lee ${ }^{2,3}$, Hyang Sook Chun ${ }^{4}$, \\ Ki Won Lee ${ }^{5}$ and Jung Han Yoon Park ${ }^{1,2^{*}}$
}

\begin{abstract}
Introduction: High-fat diets (HFDs) are known to cause obesity and are associated with breast cancer progression and metastasis. Because obesity is associated with breast cancer progression, it is important to determine whether dietary fat per se stimulates breast cancer progression in the absence of obesity. This study investigated whether an HFD increases breast cancer growth and metastasis, as well as mortality, in obesity-resistant BALB/c mice.

Methods: The 4-week-old, female BALB/c mice were fed HFD (60\% kcal fat) or control diet (CD, 10\% kcal fat) for 16 weeks. Subsequently, 4T1 mammary carcinoma cells were injected into the inguinal mammary fat pads of mice fed continuously on their respective diets. Cell-cycle progression, angiogenesis, and immune cells in tumor tissues, proteases and adhesion molecules in the lungs, and serum cytokine levels were analyzed with immunohistochemistry, Western blotting, and enzyme-linked immunosorbent assay (ELISA). In vitro studies were also conducted to evaluate the effects of cytokines on 4T1 cell viability, migration, and adhesion.

Results: Spleen and gonadal fat-pad weights, tumor weight, the number and volume of tumor nodules in the lung and liver, and tumor-associated mortality were increased in the HFD group, with only slight increases in energy intake and body weight. HF feeding increased macrophage infiltration into adipose tissues, the number of lipid vacuoles and the expression of cyclin-dependent kinase (CDK)2, cyclin D1, cyclin A, Ki67, CD31, CD45, and CD68 in the tumor tissues, and elevated serum levels of complement fragment 5a (C5a), interleukin (IL)-16, macrophage colony-stimulating factor (M-CSF), soluble intercellular adhesion molecule (sICAM)-1, tissue inhibitors of metalloproteinase (TIMP)-1, leptin, and triggering receptor expressed on myeloid cells (TREM)-1. Protein levels of the urokinase-type plasminogen activator, ICAM-1, and vascular cell adhesion molecule-1 were increased, but plasminogen activator inhibitor-1 levels were decreased in the lungs of the HFD group. In vitro assays using 4T1 cells showed that sICAM-1 increased viability; TREM-1, TIMP-1, M-CSF, and SICAM-1 increased migration; and C5a, sICAM-1, IL-16, M-CSF, TIMP-1, and TREM-1 increased adhesion.
\end{abstract}

Conclusions: Dietary fat increases mammary tumor growth and metastasis, thereby increasing mortality in obesityresistant mice.

\section{Introduction}

Breast cancer is a leading cause of cancer-associated mortality in women in the United States [1], and the incidence is increasing in the developing world. The majority of breast cancer-related death results from

\footnotetext{
* Correspondence: jyoon@hallym.ac.kr

'Department of Food Science and Nutrition, College of Natural Sciences,

Hallym University, 39 Hallymdaehak-gil, Chuncheon, 200-702, Korea

Full list of author information is available at the end of the article
}

uncontrolled metastatic disease. Although in 10\% to $15 \%$ of cases, breast cancer spreads to other parts of the body within 3 years of initial diagnosis, metastasis tends to recur later, 10 years or more after the detection of the primary tumor [2]. However, current therapies including surgery, hormone therapy, chemotherapy, radiation therapy, and selective combinations thereof are not completely effective in the treatment of metastatic breast cancer [3]. Thus, it is important to find safe and

\section{C) Biomed Central}


effective lifestyle modifications, including dietary habits, for decreasing breast cancer development and metastasis.

Epidemiologic studies indicate that consuming a highfat (regardless of fat type) diet may lead to an increased risk of invasive breast cancer in postmenopausal women [4]. High-fat diets are known to induce obesity in humans and rodents [5,6], and obese women have an increased risk of developing postmenopausal breast cancer $[7,8]$. Additionally, a high body mass index (BMI) is associated with poor prognosis in breast cancer patients $[9,10]$. Thus, it is clearly important to understand the molecular basis for the association of high-fat diet and/or obesity with breast cancer development and mortality.

In 1991 Rose et al. [11] reported that a diet containing $23 \%$ as opposed to $5 \%$ (wt/wt) corn oil (rich in the omega- 6 fatty acid linoleic acid) increased the tumor growth rate and lung-metastasis incidence of MDA-MB435 human breast cancer cells injected into the mammary fat pads of athymic nude mice. To evaluate the effects of a high-fat diet on cancer development and progression and the underlying mechanisms thereof, we used the 4T1 orthotopic model, in which 4T1 mammary carcinoma cells are injected into the mammary fat pads of immune-competent BALB/c mice. The $4 \mathrm{~T} 1$ cells were derived from the mammary tumors of BALB/C mice lacking protein expression of the estrogen receptor $\alpha[12,13]$. When injected into the mammary fat pads of syngeneic BALB/c mice, 4T1 cells grow into solid tumors that metastasize to the lung, liver, lymph nodes, and brain, while the primary tumor grows in situ $[14,15]$. The $4 \mathrm{~T} 1$ orthotopic model closely mimics the progressive forms of estrogen-insensitive human metastatic breast cancer [16]. Additionally, BALB/c mice are obesity resistant, and high-fat diet (HFD) consumption has little effect on body weight [17].

In this study we demonstrated that the prolonged consumption of an HFD without any reduction in the intake of protein, minerals, vitamins, and fiber has little effect on energy intake and body weight but does increase breast cancer growth and metastasis, as well as mortality in BALB/c mice.

\section{Materials and methods Materials}

Reagents were purchased from the following suppliers: 3-[4,5-dimethylthiazol-2-yl]-2,5-diphenyltetrazolium bromide (MTT), Bouin solution, and anti- $\beta$-actin antibody from Sigma (St. Louis, MO, USA); antibodies against CD45, matrix metalloproteinase (MMP)-9, tissue inhibitor of matrix metalloproteinase (TIMP)-2, intercellular adhesion molecule (ICAM)-1, and vascular cell adhesion molecule (VCAM)-1, and enzyme-linked immunosorbent assay (ELISA) kits for soluble ICAM-1, macrophage colony stimulating factor (M-CSF), TIMP-1, leptin, and triggering receptor expressed on myeloid cells (TREM)1 from R and D Systems (Minneapolis, MN, USA); ELISA kits for complement fragment 5a (C5a) and interleukin (IL)-16 from USCN Life Science and Technology Company (Missouri City, TX, USA); antibodies against urokinase-type plasminogen activator (uPA) from Calbiochem (La Jolla, CA, USA); antibodies against E2F1, proliferating cell nuclear antigen (PCNA), p27, cyclindependent kinase (CDK)2, CDK4, cyclin A, cyclin D1, CD31, and vascular endothelial growth factor (VEGF), plasminogen activator inhibitor (PAI)-1 from Santa Cruz Biotechnology (Santa Cruz, CA, USA); antibodies against Ki67 and F4/80 from Abcam (Cambridge, MA, USA); horseradish peroxidase-conjugated anti-rabbit, antimouse, and anti-goat IgG from Amersham Biosciences (Arlington Heights, IL, USA); an antibody against CD68 from ABBIOTEC (San Diego, CA, USA); and Immobilon Western Chemiluminescent HRP Substrate and adhesion assay kit from Millipore Corporation (Billerica, MA, USA). If not otherwise noted, all other materials were purchased from Sigma-Aldrich Co.

\section{T1 cell culture}

4T1 murine mammary carcinoma cells were acquired from the American Type Culture Collection (Manassas, MA, USA) and maintained in Dulbecco's Modified Eagle's Medium (DMEM) containing $100 \mathrm{ml} / \mathrm{L}$ of fetal bovine serum (FBS) with 100,000 U/L of penicillin and $100 \mathrm{mg} / \mathrm{L}$ of streptomycin in a humidified atmosphere of $5 \% \mathrm{CO}_{2}$ in air.

\section{Animals}

Three-week-old female BALB/c mice were purchased from Orient Bio Inc. (Seongnam, Korea) and housed at the animal research facility of Hallym University. Mice were acclimatized to the laboratory conditions and provided free access to a standard nonpurified rodent diet (Superfeed Co., Wonju, Korea) and water. The mice were acclimated for 1 week before use and maintained throughout the study in a controlled environment: $24 \pm$ $2^{\circ} \mathrm{C}, 50 \pm 10 \%$ relative humidity, and a 12-hour light/dark cycle. To determine the survival rate of animals, mice were killed when they reached moribund conditions, as described by Toth et al. [18]. All experiments were conducted in accordance with the protocols approved by the Animal Care and Use Committee of the Hallym University, Korea (Ethical approval number: Hallym 2009-122).

\section{Diets}

The mice were randomly divided into two groups; the control and high-fat groups. The purified diets used in this study were purchased from Research Diets, Inc. (New Brunswick, NJ, USA). The control diet (CD; No. D12450B) 
contained $10 \%$ of kcal from fat, and the HFDs (No. D12451 and D12452) contained 45\% and 60\% of kcal from fat. The lard content was $4.4,39.4$, and $54.4 \mathrm{kcal} \%$ in the 10,45 , and $60 \mathrm{kcal} \%$ diets, respectively. The three diets contained identical quantities of protein, cellulose, soybean oil, vitamins, and minerals per kilocalorie (Additional file 1). Fresh diet was freely provided each day, and daily feed intake was monitored throughout the study.

\section{In vivo mammary cancer orthograft model}

Twelve or 16 weeks after initiating feeding, 4T1 cells (5 $\times 10^{4}$ cells suspended in $0.1 \mathrm{ml}$ Matrigel(BD Biosciences, San Jose, CA, USA) were injected into the inguinal mammary fat pads of the mice. The mice continued on their respective diets. In experiment I, the mice were maintained for 42 days after the $4 \mathrm{~T} 1$ cell injection to monitor mammary cancer-related death, and the Kaplan-Meier curve was plotted for two dietary groups associated with mouse survival. In experiment II, 25 days after the 4T1 cell injections, the mice were killed with carbon dioxide asphyxiation, and the tumors, lungs, livers, kidneys, gonadal fat pads, and spleens were excised from the mice and weighed. The sera were prepared for ELISA.

Tumor volumes were measured with a set of calipers and calculated by using the following formula: $0.52 \times$ long diameter $\times$ short diameter ${ }^{2}$ [19]. The tumors and gonadal fat pads were formalin fixed and paraffin embedded for immunohistochemistry (IHC) or homogenized to prepare the tissue lysates [20] for Western blot analysis. The lungs and livers were fixed in Bouin solution or homogenized to prepare the tissue lysates [20]. Metastatic nodules in the lungs and livers were counted, and the total tumor volumes were estimated as described previously [21,22].

\section{Immunohistochemistry}

Paraffin-embedded tumor tissues were sectioned, deparaffinized, rehydrated, incubated in $3 \% \mathrm{H}_{2} \mathrm{O}_{2}$, and blocked with $5 \%$ BSA, as previously described [23]. IHC was conducted with the indicated antibodies, biotinylated rabbit anti-mouse IgG, streptavidin-horseradish peroxidase, 1,3 -diaminobenzidine (DAB) tetrahydrochloride, and hematoxylin, as described previously [23]. Randomly chosen fields were photographed at $\times 200$ magnification, and immuno-positive cells and staining intensities were quantified with a Carl Zeiss AxioImager microscope and Image M1 Software (Carl Zeiss, Jena, Germany).

\section{Western blot analysis}

Western blot analyses were conducted as described previously [24]. Signals were detected through enhanced chemiluminescence by using Immobilon Western
Chemiluminescent HRP Substrate (Millipore Corporation). The relative abundance of each band was quantified by using the Bio-profile Bio-1D application (VilberLourmat, Marine la Vallee, France), and the expression levels were normalized to $\beta$-actin.

\section{Mouse cytokine antibody array}

Pooled sera from each group were applied to a proteome profiler antibody array kit (R\&D Systems) to evaluate cytokine expression, in accordance with the manufacturer's instructions. The relative abundance of each protein was quantified by using the Bio-profile Bio1D application (Vilber-Lourmat), and the expression levels were normalized to the control protein.

\section{Enzyme-linked immunosorbent assay}

The levels of C5a, sICAM-1, IL-16, M-CSF, TIMP-1, leptin, and TREM-1 in sera were estimated by using the relevant ELISA kits according to the manufacturers' instructions.

\section{Cell-viability assay}

$4 \mathrm{~T} 1$ cells were plated in 24-well plates at $5 \times 10^{4}$ cells/ well in DMEM supplemented with $100 \mathrm{ml} / \mathrm{L} \mathrm{FBS}$. One day later, the monolayers were serum deprived with DMEM supplemented with $10 \mathrm{ml} / \mathrm{L}$ charcoal-stripped FBS (serum-deprivation medium) for 24 hours, and the cells were incubated in serum-deprivation medium in the absence or presence of various cytokines. Viable cell numbers were estimated with an MTT assay, as described previously [25].

\section{In vitro migration assay}

The cell-migration assay was conducted as described previously [26]. Serum-deprived cells were plated onto the filter in 6.5 -mm transwell inserts in 24-well plates at $5 \times 10^{4}$ cells/filter and treated for 16 hours with various cytokines in serum-deprivation medium. Migrated cells were stained with hematoxylin and eosin ( $\mathrm{H} \& \mathrm{E})$, and then counted under a light microscope in eight randomized fields.

\section{Adhesion assay}

4T1 cells were plated in human collagen type I-coated CytoMatrix Cell Adhesion Strips at $1 \times 10^{5}$ cells. Cells were incubated in DMEM containing $10 \mathrm{ml} / \mathrm{L}$ of charcoal-stripped FBS with various cytokines at $37^{\circ} \mathrm{C}$ for 45 minutes. Cells were stained with crystal violet, and the cell-bound stains were quantified by measuring the absorbance at $570 \mathrm{~nm}$, as described previously [26].

\section{Statistical analysis}

The data were expressed as the mean \pm SEM. The significance of the difference between groups was evaluated 
with the Student $t$ test, by using SAS for Windows version 9.1 (SAS Institute). Differences were considered significant at $P<0.05$. The Kaplan-Meier curves were analyzed with a Log-Rank test to assess the significance of the differences in the survival rates of the mice.

\section{Results}

Prolonged high-fat diet consumption increases mammary cancer-related mortality in BALB/c mice injected with $4 \mathrm{~T} 1$ cells

The first study determined mortality rates in $4 \mathrm{~T} 1$ cellinjected mice fed HFD (45\%). Relative to the mice fed on the CD (10\% kcal as fats), the survival rate was lower in the mice fed HFD $(P<0.001$; Figure $1 \mathrm{a})$. In the subsequent study, the mice were fed on a $60 \% \mathrm{kcal}$-diet or the $\mathrm{CD}$ for 16 weeks and then injected with 4T1 cells. Again, survival rates were reduced in the mice fed on the HFD $(60 \% \mathrm{kcal})$ as compared with controls $(P<$ 0.001 , Figure $1 \mathrm{~b})$.

\section{Long-term consumption of a $60 \% \mathrm{kcal}$-fat diet increases solid tumor growth of $4 \mathrm{~T} 1$ cells in BALB/c mice}

Body weights were slightly higher in the mice fed on the $60 \%$ kcal-fat diet than in controls from 1 week onward after initiating experimental diets (Figure 1c). Final body weights were $24.7 \pm 0.3 \mathrm{~g}$ and $26.2 \pm 0.5 \mathrm{~g}$ in the control and high-fat groups. Energy intakes were only slightly higher in the high-fat group (Figure 1d). Spleen and gonadal fat-pad weights were significantly higher in the HFD-fed mice. However, the weights of the liver, lung, and kidney were unaffected by prolonged feeding on the HFD (Table 1). The subcutaneous fat, mesenteric fat, and retroperitoneal fat were almost undetectable to the naked eye in the BALB/c mice fed on either the CD or HFD. The wet weight of the primary solid tumors was increased by $22.4 \%(P<0.0047)$, and tumor volume, increased by $28.0 \%(P<0.0022)$ in HFD-fed mice compared with controls (Figure 1e, f).

\section{Long-term consumption of a $60 \% \mathrm{kcal}$-fat diet increases} cancer cell proliferation, angiogenesis, and infiltration of immune cells in 4T1 tumors in BALB/c mice

IHC staining revealed that the HFD-fed mice had significantly increased expression of Ki67 $(P<0.0084)$, CDK2 $(P<0.0152)$, cyclin D1 $(P<0.0381)$, and cyclin A $(P<$ 0.0284 ) relative to controls (Figure $2 \mathrm{a}, \mathrm{b}$ ). Western blotting showed that the expression levels of PCNA and E2F1 were increased by $72.0 \%(P<0.017)$ and $90.0 \%(P$ $<0.05)$, respectively, in the tumor tissues of HFD-fed mice relative to controls. In contrast, p27 (Kip1) expression was reduced significantly in the HFD-fed mice (Figure $2 \mathrm{c}$ ).

IHC staining showed that the expressions of CD31, VEGF, CD68, and CD45 were markedly increased in the tumors of the HFD-fed mice compared with controls (Figure 3a,b). H\&E staining showed that the number of lipid vacuoles increased in the tumor tissues of the HFD-fed mice (Figure 3a, b). The number of F4/80+ cells was significantly increased in the gonadal fat pads of mice fed on the HFD (Figure 3c).

\section{Prolonged consumption of a $60 \% \mathrm{kcal}-\mathrm{fat}$ diet increases lung and liver metastasis of $4 \mathrm{~T} 1$ cells in BALB/c mice} Tumor nodules grew in all mice in both groups, but in HFD-fed mice, the number and volume of tumor nodules on the lung increased by $65.2 \%(P<0.0298)$ and $159.9 \%(P<0.05)$, respectively, as compared with the mice fed on the CD (Figure 4a-c). In the liver, the incidence of tumor nodules was $35.7 \%$ and $66.7 \%$ in the CD group and HFD groups, respectively; and the number of nodules was $844 \%(P<0.0159)$ greater in the HFD-fed mice. Additionally, long-term consumption of the HFD resulted in a $1,568 \%(P<0.0188)$ increase in the volume of tumor nodules in the liver as compared with controls (Figure 4d-f).

\section{A $60 \% \mathrm{kcal}-\mathrm{fat}$ diet alters the expression of proteins involved in metastasis in the lungs of BALB/c mice injected with $4 \mathrm{~T} 1$ cells}

Western blot analysis of lung tissue lysates revealed that HFD increased the protein levels of UPA, ICAM-1, and VCAM-1 in the lungs by $98.0 \%(P<0.0089), 89.0 \%(P<$ $0.008)$, and $63.0 \%(P<0.0069)$, respectively, as compared with control mice, whereas a significant $(P<0.05)$ reduction of PAI-1 expression was noted in the mice fed HFD (Figure 5)

A $60 \%$ kcal-fat diet increases serum levels of C5a, sICAM1, IL-16, M-CSF, TIMP-1, leptin, and TREM-1 in BALB/C mice injected with $4 \mathrm{~T} 1$ cells

Because a variety of cytokines are known to affect the processes of breast cancer growth and metastasis (reviewed in [27]), the serum cytokines levels were estimated by using a mouse cytokine antibody array kit. Among the 40 cytokines measurable with the mouse cytokine array kit, seven cytokines (C5a, sICAM-1, IL16, G-CSF, M-CSF, TIMP-1, and TREM-1) were detected in the sera of mice. The levels of C5a, sICAM1, IL-16, M-CSF, TIMP-1, and TREM-1 were increased in the sera of the HFD-fed mice relative to those of the controls, whereas the level of granulocyte colony-stimulating factor (G-CSF) was not altered (data not shown). We subsequently confirmed the results with ELISA and noted changes similar to those observed in the antibody array. HFD increased serum levels of C5a, sICAM-1, IL16, M-CSF, TIMP-1, and TREM-1 by $31.8 \%(P<0.05)$, 31.8\% $(P<0.0002), 26.0 \%(P<0.002), 61.0 \%(P<$ $0.0001), 40.9 \%(P<0.0032)$, and $41.3 \%(P<0.002)$, 

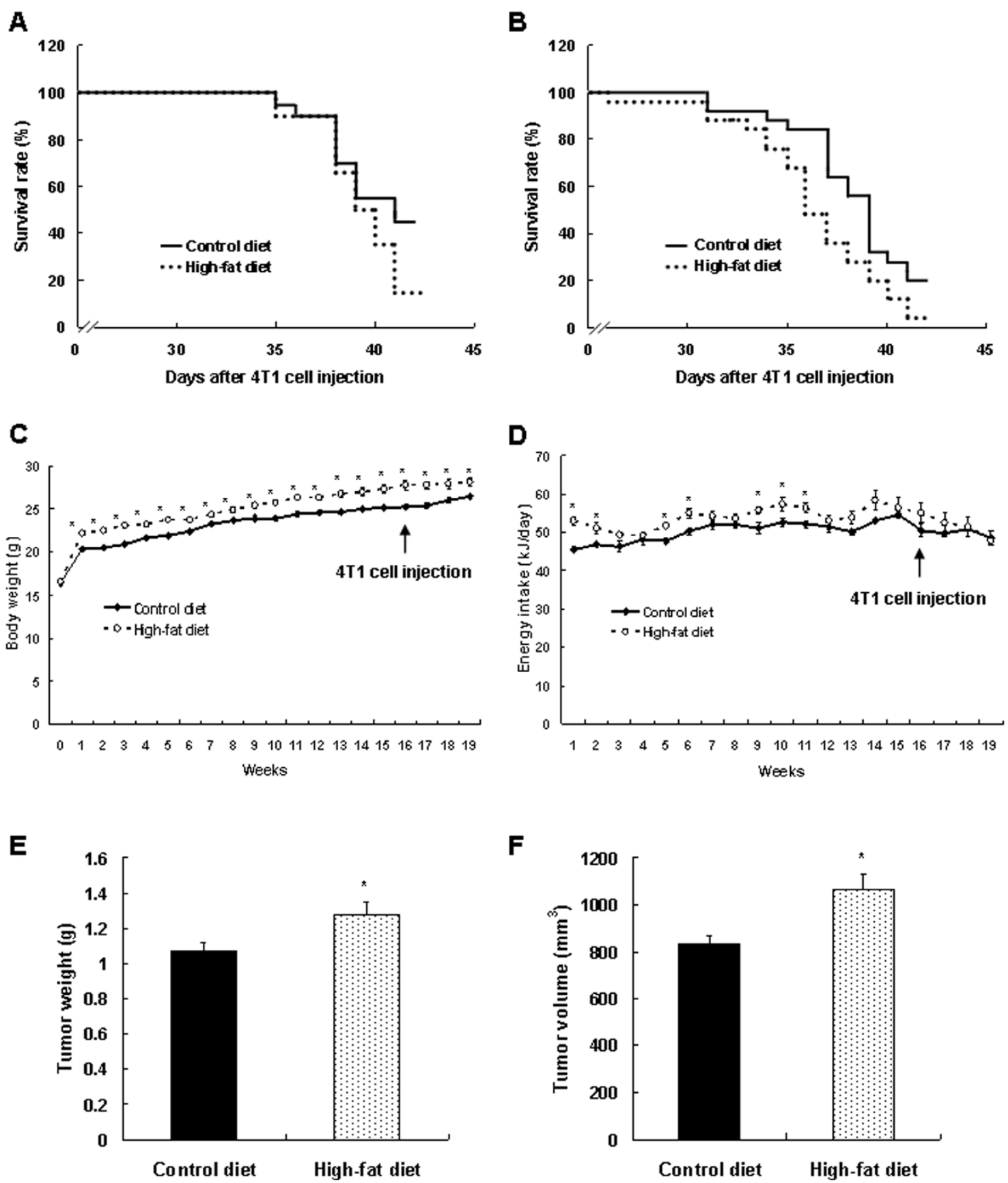

Figure $1 \mathrm{~A}$ high-fat diet reduces the survival rate and increases solid tumor growth in BALB/c mice injected with 4T1 cells. (a) Fourweek-old, female BALB/c mice were fed on a high-fat diet in which $45 \%$ of the kilocalories were provided as fats or a control diet in which $10 \%$ of kilocalories were provided as fats for 12 weeks. Twelve weeks after initiating feeding, $4 \mathrm{~T} 1$ cells $\left(5 \times 10^{4}\right.$ cells suspended in $0.1 \mathrm{ml}$ gelatinous protein (Matrigel) were injected into the inguinal mammary fat pads of the mice. The mice were fed continuously on the same diets. Survival rates were monitored after the 4T1 cell injection ( 0 day). (b) Four-week-old, female BALB/c mice were fed on a high-fat diet in which $60 \%$ of the kilocalories were provided as fats or the control diet (10\% kcal fat) for 16 weeks. Sixteen weeks after the initiation of feeding, 4T1 cells were injected, and mice were continuously fed on the same diet. (c-f) Mice were fed on the diets and injected with $4 \mathrm{T1}$ cells, as described in $\mathbf{b}$ except that they were killed 25 days after the 4T1 cells injection. (c) Body weights of mice were measured every week. Each point of body weight represents the mean $\pm \operatorname{SEM}(n=30)$. (d) Energy intake was calculated on the basis of $16.12 \mathrm{~kJ} / \mathrm{g}$ in the control diet and $21.93 \mathrm{~kJ} / \mathrm{g}$ in the high-fat diet. Each point of energy intake represents the mean \pm SEM $(n=6)$. *Significantly different from the control group, $P<0.05$. (e) The tumors were excised from mice and weighed. (f) The tumor volume was measured by using calipers and calculated with the formula: $0.52 \times$ long diameter $\times$ short diameter ${ }^{2}$. Each bar represents the mean $\pm \operatorname{SEM}(n=30)$. *Significantly different from the control group, $P<0.05$. 
Table 1 Effect of chronic consumption of a high-fat diet on organ weights in BALB/c mice injected with 4T1 cells

\begin{tabular}{lll}
\hline & Control diet & High-fat diet \\
\hline Liver $(\mathrm{g})$ & $1.34 \pm 0.02$ & $1.35 \pm 0.03$ \\
Lung $(\mathrm{g})$ & $0.28 \pm 0.01$ & $0.30 \pm 0.01$ \\
Kidney, right (g) & $0.16 \pm 0.01$ & $0.16 \pm 0.01$ \\
Kidney, left (g) & $0.16 \pm 0.01$ & $0.16 \pm 0.01$ \\
Spleen (g) & $0.81 \pm 0.04$ & $1.02 \pm 0.04^{\mathrm{a}}$ \\
Gonadal fat pad (g) & $0.19 \pm 0.02$ & $0.25 \pm 0.04^{\mathrm{a}}$
\end{tabular}

Mice were fed on the high-fat $(60 \% \mathrm{kcal})$ or control diet $(10 \% \mathrm{kcal})$ for 16 weeks and injected with $4 \mathrm{~T} 1$ cells, as described in Materials and Methods. Twenty-five days after the injection of $4 \mathrm{~T} 1$ cells, the mice were killed, and the lungs, livers, kidneys, spleens, and gonadal fat pads were excised from the mice and weighed. Values represent the means \pm SEM $(n=30)$. ${ }^{a}$ Significantly different from the control group, $P<0.05$.

respectively, relative to control mice. HFD also increased the serum levels of leptin by $36.0 \%(P<0.0013)$ relative to controls (Table 2).

Various cytokines elevated by HFD increased the viability, adhesion, and migration of $4 \mathrm{~T} 1$ cells in vitro

We next conducted in vitro assays to determine the effects of the cytokines that were elevated in vivo by HFD on the viability, adhesion, and migration of 4T1 cells. The concentrations of cytokines used in these assays were the mean concentrations detected in the sera of the HFD-fed mice (Table 2). Among these cytokines, only sICAM-1 enhanced the viability of $4 \mathrm{~T} 1$ cells (Figure 6a). The capacity of the $4 \mathrm{~T} 1$ cells to adhere to strips coated with human collagen type I was increased by C5a, sICAM-1, IL-16, M-CSF, TIMP-1, and TREM-1 (Figure 6b). Additionally, TREM-1, TIMP-1, M-CSF, and sICAM-1 significantly increased the migration of 4T1 cells (Figure 6c).

\section{Discussion}

The principal objective of this study was to determine whether dietary fat increases mammary tumor growth and metastasis as well as mammary cancer-associated mortality in obesity-resistant BALB/c mice. BALB/c mice fed on the $60 \% \mathrm{kcal}$-fat diet consumed less food, such that their intake of protein, vitamins, minerals, fiber, and kilocalories was only slightly increased relative to that of the control mice. Epidemiologic evidence indicates that the consumption of fiber, vegetable, and micronutrients is associated with reduced mortality in postmenopausal women diagnosed with breast cancer [28]. Other previous findings also suggested the possible benefits of a low-fat/highvegetable diet on disease-free survival (reviewed in [29]). The present results clearly show that increased dietary fat intake, without decreasing other nutrients (except for carbohydrates) and with little effect on energy intake and weight, increases mammary cancer growth, angiogenesis, metastasis, and mortality of BALB/c mice with implanted tumors.

$\mathrm{Xu}$ et al. [30] demonstrated that a variety of inflammatory and macrophage-specific genes are upregulated dramatically in white adipose tissues of C57BL/6J mice fed a $60 \%$ kcal diet for 16 weeks. Their control and high-fat diets were probably similar to those used in this study because they were supplied by the same manufacturer. Thus, in the current study, before the injection of 4T1 mammary cancer cells, obesity-resistant BALB/c mice were fed a $60 \% \mathrm{kcal}$-fat diet for 16 weeks to induce chronic low-grade inflammation. We noted that the body weights were only slightly increased in the BALB/c mice fed on the HFD. At the end of the experiment, the change in body weight due to the long-term high-fat feeding was measured at only $4 \%$ after correction for differences in tumor and spleen weights. At autopsy, we were unable to detect visible adipose tissues except in the gonadal fat pad, the weight of which was increased in the HFD-fed mice. These results contrast markedly from those reported by $\mathrm{Xu}$ et al. [30], who demonstrated that HFD markedly increased the body weights of C57BL/6J mice. This discrepancy between the results was anticipated, however, because $\mathrm{C} 57 \mathrm{BL} / 6$ mice are obesity susceptible, and BALB/C mice are obesity resistant [17]. Macrophage accumulation was noted in the adipose tissues of C57BL/6J mice fed on an HFD [31]. In this study, we noted that F4/80+ macrophage infiltration in the gonadal fat pad and the serum levels of cytokines (C5a, sICAM-1, IL-16, M-CSF, TIMP-1, and TREM-1) were elevated in HFD-fed mice (Table 2). These results indicate that dietary fat induces a lowgrade inflammation in the absence of obesity, and a small increase in adipose tissue may have contributed to the induction of inflammation.

Leptin is a cytokine-like protein secreted from adipose tissue [32], and circulating leptin levels are positively associated with body weight and/or body fat $[33,34]$. Leptin and leptin receptor are involved in the development of normal mammary glands and in the progression of breast cancer [35-37]. In this study, we found that the serum levels of leptin were elevated in HFD-fed mice without a discernible change in body weight, indicating that a small increase in fat mass increases serum leptin levels, and the elevated leptin may have contributed to the stimulation of mammary cancer progression in these mice.

The increased expression of CD31 and VEGF in tumor tissues (Figure 3a) indicates that tumor angiogenesis increased in the HFD-fed mice. Recent evidence indicates that in addition to the interactions of cancer cells and endothelial cells, inflammatory cells also play an important role in the formation of the blood vessels that nourish a growing tumor (reviewed in [38]). Tumor-associated immune cells, including macrophages, 


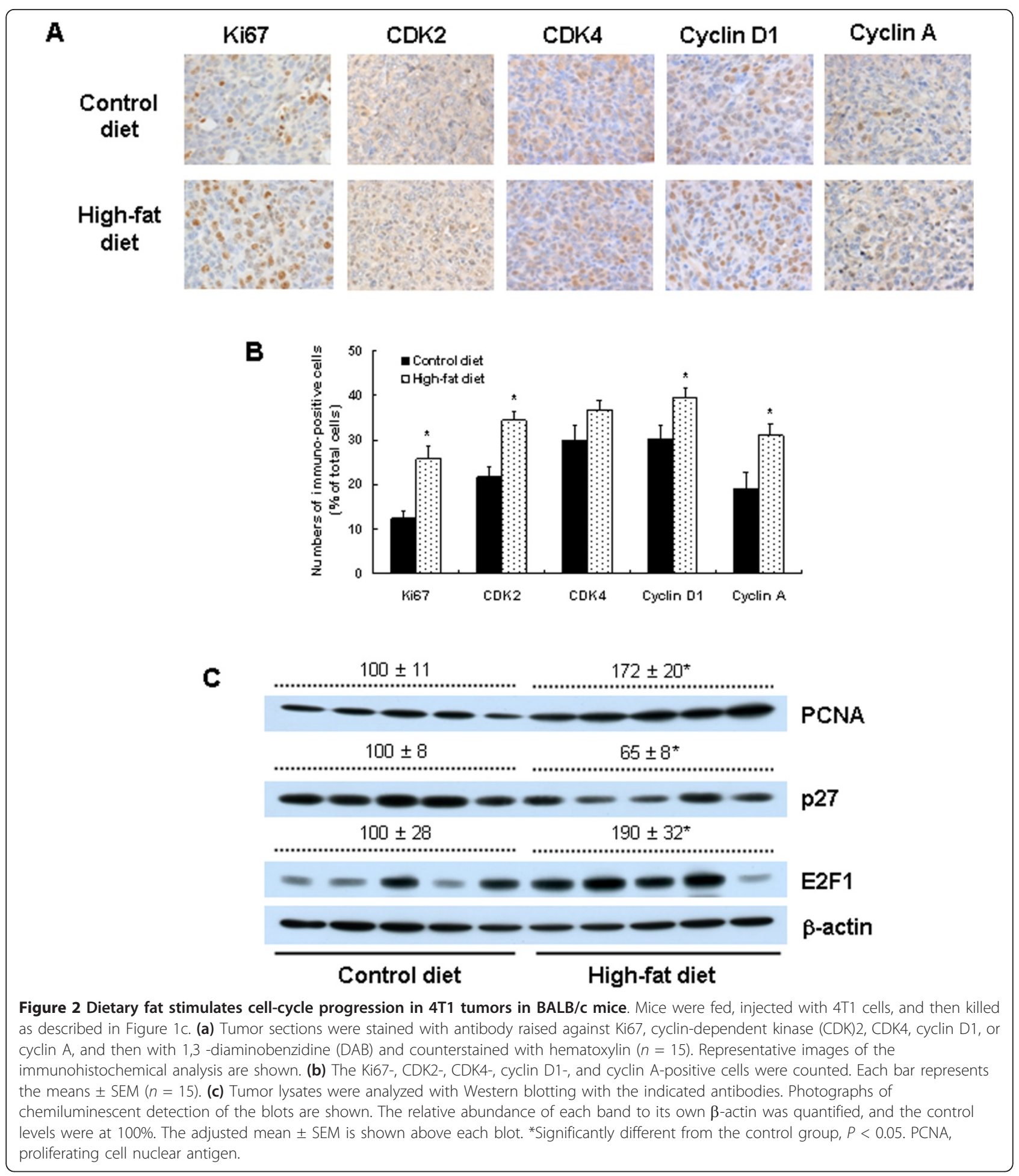

granulocytes, and mast cells, have been shown to stimulate tumor angiogenesis (reviewed in [39]). Additionally, a significant positive correlation between the degree of angiogenesis and the number of CD68+ cells has been demonstrated in human breast carcinoma [40]. The number of CD45+ and CD68+ cells was markedly increased in the tumor tissues of HFD-fed mice (Figure $3 a)$, indicating increased infiltration of these immune cells into tumor tissues, which possibly increased tumor angiogenesis.

In this study, we noted that blood levels of various cytokines were increased in the HFD-fed mice (Table 2). 


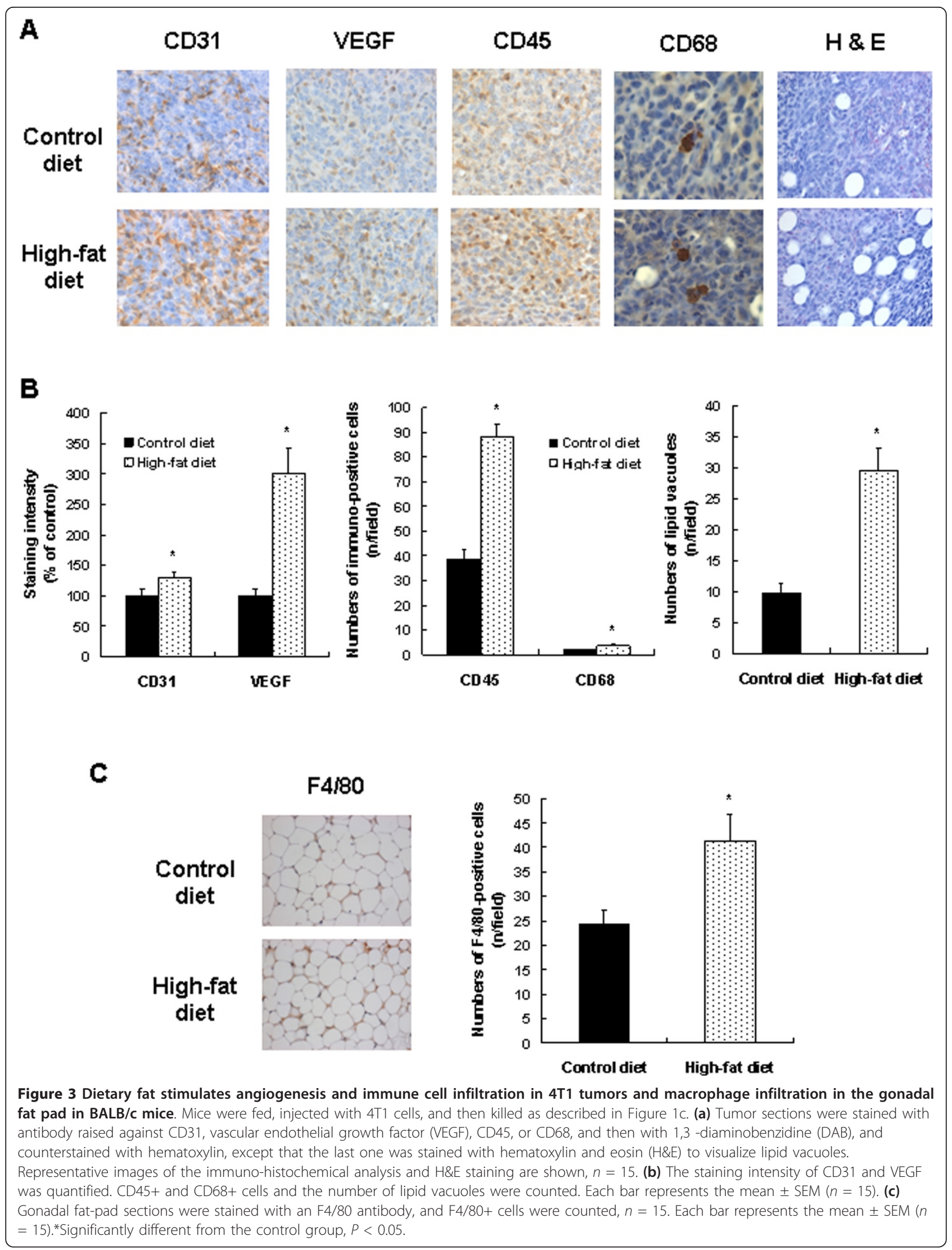




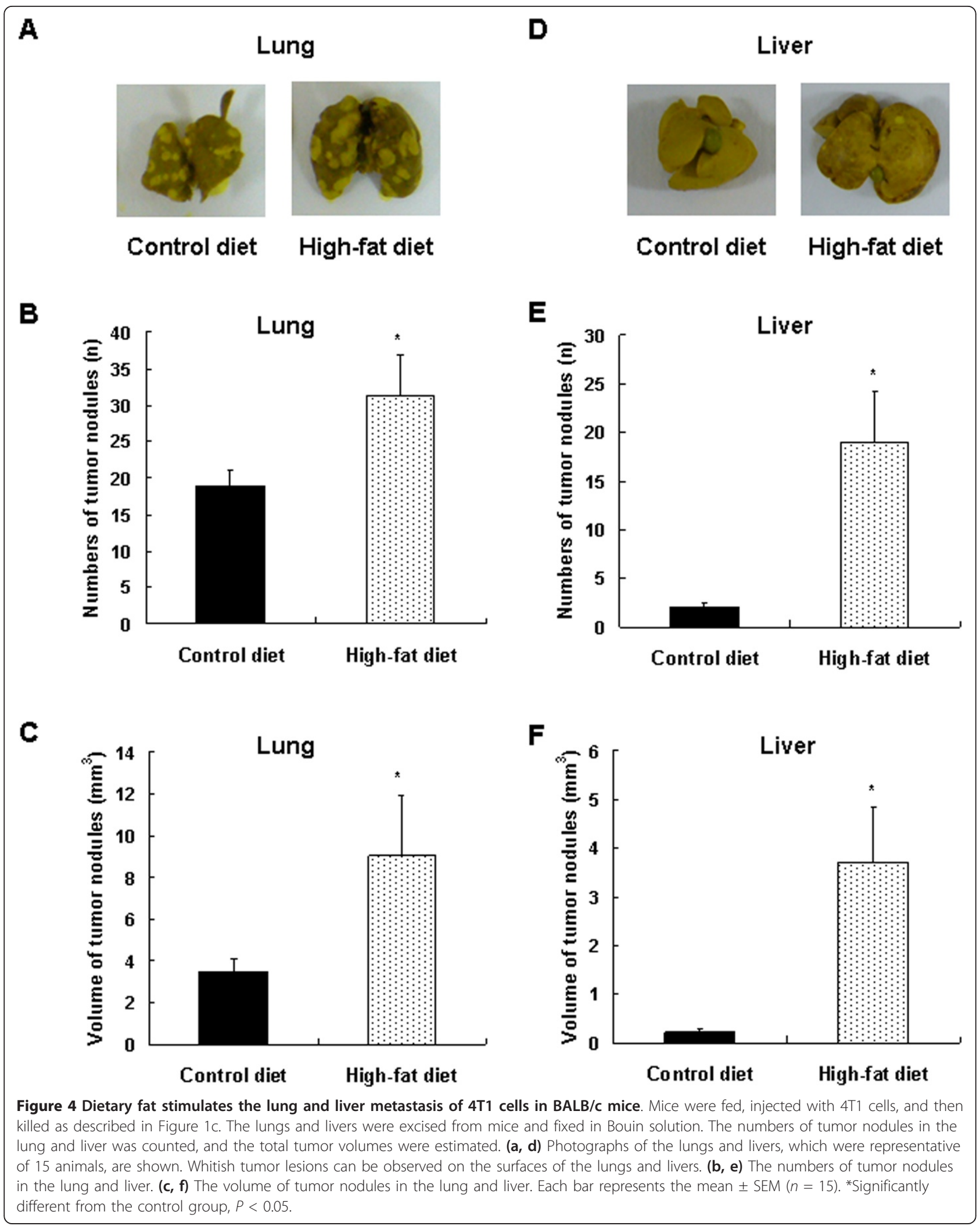




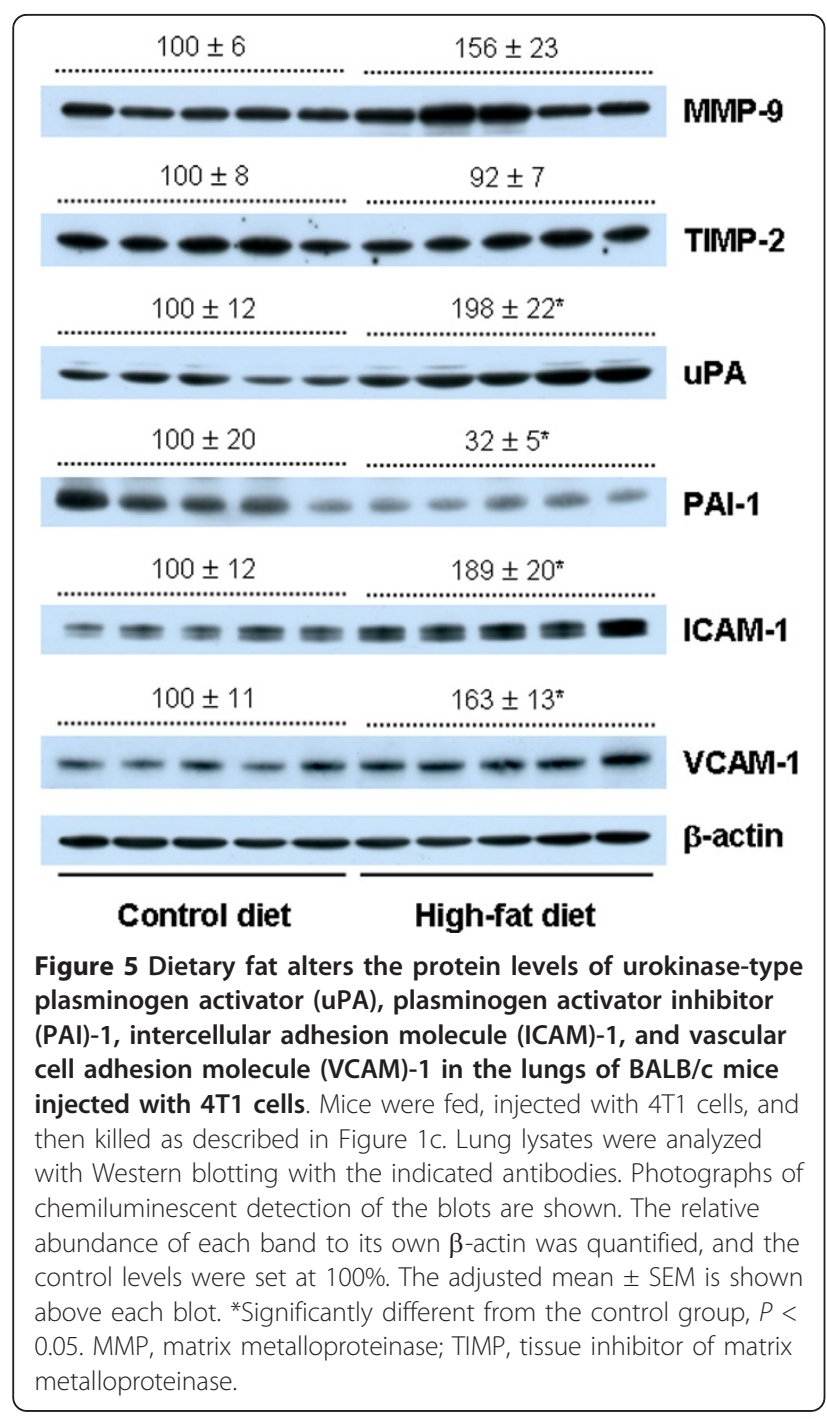

Our in vitro studies demonstrated that some of these cytokines stimulated the growth, migration, and adhesion of 4T1 mammary cancer cells (Figure 6). These results indicate that the increased cytokine levels may have contributed to changes in the expression of metastasis-related proteins (uPA, ICAM-1, and VCAM-1), thereby increasing metastasis. Future studies are needed to determine which types of cells secrete these cytokines in tumors, adipose tissues, the lungs, and/or the liver.

It was previously reported that adipocytes promote breast carcinoma cell growth in collagen gels by the cancer-stromal interaction [41]. Additionally, when coinjected with SUM159PT mammary adenocarcinoma cells in athymic nude mice, fully differentiated 3T3-L1 adipocytes stimulate tumor growth and lung metastasis [42]. We observed increased numbers of lipid vacuoles in the tumor tissues of HFD-fed mice (Figure 3a). Along with the tumor cells, these adipocytes may participate in
Table 2 Effect of prolonged consumption of a high-fat diet on the levels of various cytokines in the sera of BALB/c mice injected with $4 T 1$ cells

\begin{tabular}{lll}
\hline & Control diet & High-fat diet \\
\hline C5a $(\mathrm{ng} / \mathrm{ml})$ & $22.0 \pm 2.7$ & $29.0 \pm 3.1^{\mathrm{a}}$ \\
sICAM-1 $(\mathrm{ng} / \mathrm{ml})$ & $494.2 \pm 22.6$ & $651.5 \pm 29.4^{\mathrm{a}}$ \\
IL-16 $(\mathrm{ng} / \mathrm{ml})$ & $150.8 \pm 8.0$ & $190.0 \pm 8.4^{\mathrm{a}}$ \\
M-CSF $(\mathrm{pg} / \mathrm{ml})$ & $714.1 \pm 29.3$ & $1,149.5 \pm 35.6^{\mathrm{a}}$ \\
TIMP-1 $(\mathrm{ng} / \mathrm{ml})$ & $4.4 \pm 0.4$ & $6.2 \pm 0.4^{\mathrm{a}}$ \\
TREM-1 $(\mathrm{pg} / \mathrm{ml})$ & $684.7 \pm 17.8$ & $967.8 \pm 21.6^{\mathrm{a}}$ \\
Leptin $(\mathrm{ng} / \mathrm{ml})$ & $138.0 \pm 0.04$ & $187.8 \pm 11.3^{\mathrm{a}}$ \\
\hline
\end{tabular}

Mice were fed on the high-fat $(60 \% \mathrm{kcal})$ or control diet $(10 \% \mathrm{kcal})$ for 16 weeks and injected with 4T1 cells, as described in Materials and Methods. At 25 days after the 4T1 cells injection, blood samples were collected from the mice, and the sera were prepared. The serum levels of complement fragment 5a (C5a), soluble intercellular adhesion molecule (sICAM)-1, interleukin (IL)-16, macrophage colony-stimulating factor (M-CSF), tissue inhibitor of matrix metalloproteinase (TIMP)-1, triggering receptor expressed on myeloid cells (TREM)-1, and leptin were measured with the appropriate ELISA kits. Values

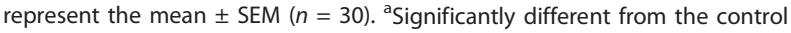
group, $P<0.05$.

the recruitment of immune cells into the tumor. The crosstalk between tumor cells, adipocytes, and immune cells within the tumors of the HFD-fed mice (Figure 3a) may have produced a broad variety of growth factors, cytokines, and chemokines, resulting in changes in the expression of proteins involved in the stimulation of cell-cycle progression of tumor cells (Ki67, PCNA, CDK2, CDK4, cyclin A, and cyclin D) and angiogenesis (VEGF) (Figure 2a-c, 3a). Additionally, the increase in new blood vessels may have supplied nutrients and growth factors for the stimulation of cell-cycle progression in addition to the stimulation of metastasis. In this study, the direct mechanism by which HFD feeding induces the expression of metastasis-regulating proteins, cyclins, and CDKs in the tumor tissues was not fully elucidated.

In this study, we noted that the weights of spleen were increased in the HFD-fed mice (Table 1), which was accompanied by increases in the serum levels of C5a, IL-16, sICAM-1, M-CSF, TIMP-1, TREM-1, and leptin (Table 2). Splenomegaly was invariably observed in 4T1tumor-bearing mice [43-45], and correlated strongly with increased extramedullary hematogenesis and metastasis in the spleen and circulating levels of neutrophils and leukocytes [46]. It has been reported that 4T1 tumor growth is associated with increased splenomegaly or splenomegaly-associated inflammation, and various tumor-derived cytokines, such as G-CSF, GM-CSF, and IFN- $\gamma$, may be responsible for the splenomegaly in mice injected with 4T1 cells [44]. Future studies are needed to determine whether the increases in C5a, IL-16, sICAM-1, M-CSF, TIMP-1, TREM-1, and/or leptin are responsible for the increased splenic mass in HFD-fed mice. 

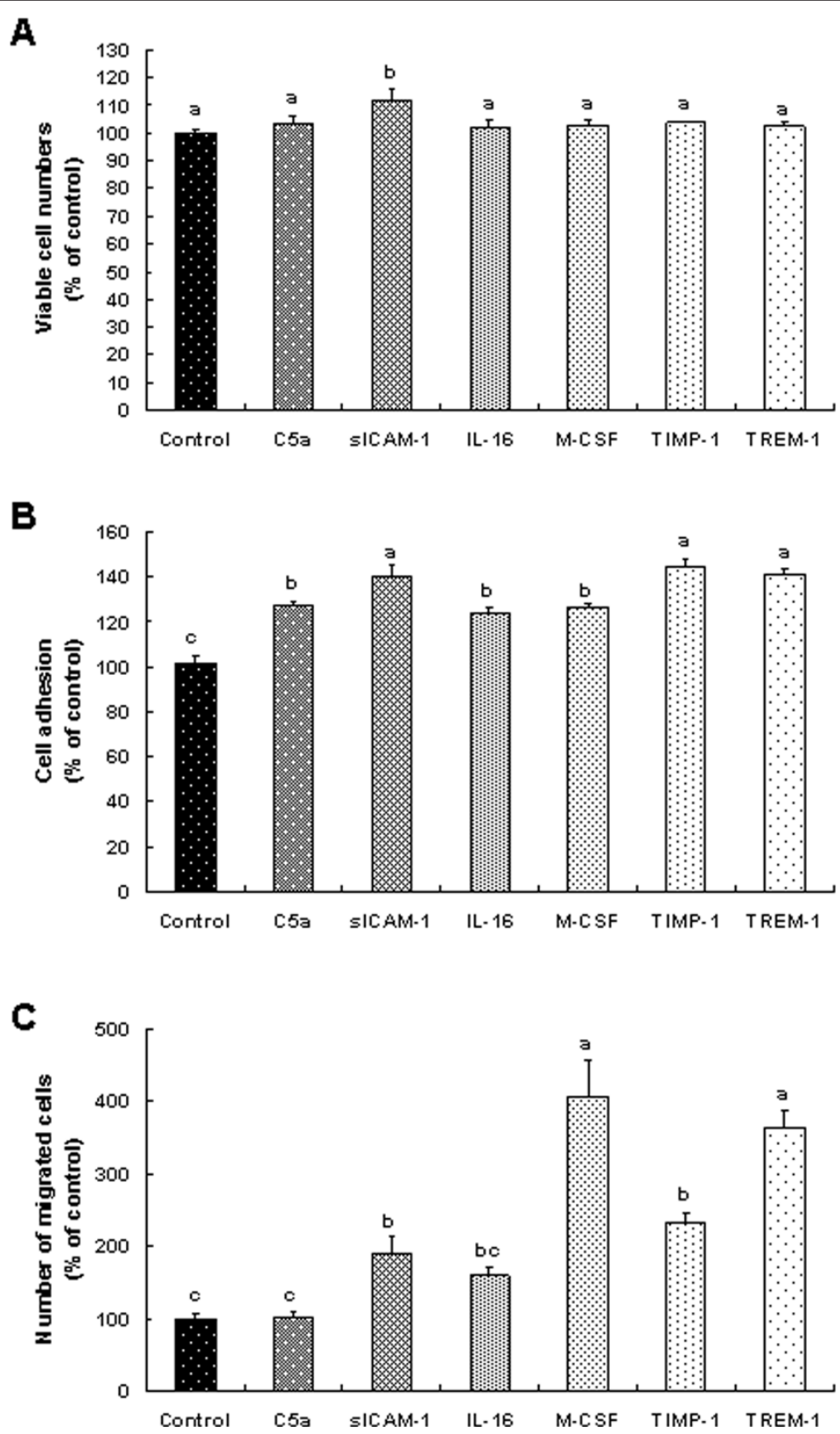

Figure 6 Effect of various cytokines on proliferation (a), adhesion (b), and migration (c) of 4T1 cells in vitro. (a) 4T1 cells were plated in 24-well plates at $5 \times 10^{4}$ cells/well in DMEM supplemented with $100 \mathrm{ml} / \mathrm{L}$ FBS. One day later, the monolayers were serum deprived with DMEM supplemented with $10 \mathrm{ml} / \mathrm{L}$ charcoal-stripped FBS (serum-deprivation medium) for $24 \mathrm{~h}$. After serum deprivation, the cells were incubated in serum-deprivation medium in the absence or presence of $29 \mathrm{ng} / \mathrm{ml}$ complement fragment 5a (C5a), $652 \mathrm{ng} / \mathrm{ml}$ soluble intercellular adhesion molecule (sICAM)-1, $190 \mathrm{ng} / \mathrm{ml}$ interleukin (IL)-16, 1,150 pg/ml macrophage colony-stimulating factor (M-CSF), $6.2 \mathrm{ng} / \mathrm{ml}$ tissue inhibitor of matrix metalloproteinase (TIMP)-1, and $970 \mathrm{pg} / \mathrm{ml}$ triggering receptor expressed on myeloid cells (TREM)-1 for 24 hours. Viable cell numbers were estimated. Each bar represents the mean \pm SEM $(n=3)$. Means without a common letter differ, $P<0.05$. (b) Cells were plated in human collagen type I-coated CytoMatrix Cell Adhesion Strips and incubated with or without various cytokines (the identical concentrations of cytokines used in Figure 6a) in DMEM containing $10 \mathrm{ml} / \mathrm{L}$ charcoal-stripped FBS at $37^{\circ} \mathrm{C}$ for $45 \mathrm{~min}$. The cells were stained with crystal violet, and the cellbound stains were quantified by determining the absorbance at $570 \mathrm{~nm}$. Each bar represents the mean $\pm \operatorname{SEM}(n=7)$. Means without a common letter differ, $P<0.05$. (c) Cells were serum deprived in DMEM supplemented with $10 \mathrm{ml} / \mathrm{L}$ charcoal-stripped FBS for 24 hours. Serumdeprived cells were plated onto the filter in $6.5-\mathrm{mm}$ transwell inserts in 24 -well plates at $5 \times 10^{4}$ cells/filter. Before the plating of the cells, the lower side of the transwell filter was precoated with type IV collagen. The lower chamber of the well was filled with DMEM containing $100 \mathrm{ml} / \mathrm{L}$ gelatinase-free charcoal-stripped FBS with or without various cytokines (the identical concentrations of cytokines used in Figure 6a). The cells were incubated for 16 hours. Migrated cells were stained with hematoxylin and eosin. Each bar represents the mean \pm SEM $(n=3)$. Means without a common letter differ, $P<0.05$. 


\section{Conclusions}

This study clearly demonstrated that dietary fat increases mammary cancer growth, metastasis, and mammary cancer-associated mortality in obesity-resistant mice. We also demonstrated that dietary fat increases the expression of proteins (Ki67, CDKs, and cyclins) involved in the regulation of cell-cycle progression as well as increases in the expression of CD31, VEGF, CD68, and CD45 in tumor tissues, thereby indicating that increases in immune cell infiltration and angiogenesis stimulate cell-cycle progression and the metastasis of tumor cells. Additionally, increases in protease ( $\mathrm{uPA}$ ) and adhesion molecules (ICAM-1, VACM) may contribute to lung metastasis in HFD-fed mice. Furthermore, increases in the serum levels of cytokines may stimulate mammary cancer metastasis in HFD-fed mice. Our results suggest that dietary fat may increase breast cancer progression, even in individuals who maintain a healthy body weight, and that replacing dietary fat with carbohydrates may delay the progression of breast cancer, thereby reducing breast cancer-associated mortality.

\section{Acknowledgements}

This study was supported by the Mid-career Researcher Program (grant number 2010-0006923) and the SRC program (Center for Food \& Nutritional Genomics: grant number 2010-0001886) of the National Research Foundation (NRF) of Korea, funded by the Ministry of Education, Science, and Technology.

\section{Additional material}

Additional file 1: Supplementary Table 1. Compositions of

experimental diets

\section{Abbreviations}

C5a: complement fragment 5a; CDK: cyclin-dependent kinase; DAB: 1,3 -diaminobenzidine; DMEM: Dulbecco's Modified Eagle's Medium; ELISA: enzyme-linked immunosorbent assay; FBS: fetal bovine serum; ICAM: intercellular adhesion molecule; IL: interleukin; M-CSF: macrophage colonystimulating factor; MMP: matrix metalloproteinase; MTT: 3-[4,5dimethylthiazol-2-yl]-2,5-diphenyltetrazolium bromide; PAl: plasminogen activator inhibitor; PCNA: proliferating cell nuclear antigen; TIMP: tissue inhibitor of matrix metalloproteinase; TREM: triggering receptor expressed on myeloid cells; uPA: urokinase-type plasminogen activator; VCAM: vascular cell-adhesion molecule; VEGF: vascular endothelial growth factor.
\end{abstract}

\section{Author details}

'Department of Food Science and Nutrition, College of Natural Sciences, Hallym University, 39 Hallymdaehak-gil, Chuncheon, 200-702, Korea. ${ }^{2}$ Center for Efficacy Assessment and Development of Functional Foods and Drugs, Hallym University, 39 Hallymdaehak-gil, Chuncheon, 200-702, Korea. ${ }^{3}$ Department of Biochemistry, College of Medicine, Hallym University, 39 Hallymdaehak-gil, Chuncheon, 200-702, Korea. ${ }^{4}$ Korea Food Research Institute, 516 Baekhyun-dong, Bundang-gu, Sungnam, 463-746, Korea. ${ }^{5}$ Department of Agricultural Biotechnology and Center for Agricultural
Biomaterials, Seoul National University, 1 Gwanak-ro, Gwanak-gu, Seoul, 151921, Korea.

\section{Authors' contributions}

MRC, HP, MK, and JEH carried out the majority of animal studies, including evaluation of food consumption, tumor volumes, mortality, Western blotting, immunohistochemistry, ELISA, and metastasis. JYL, HSC, and KWL were responsible for conception of the project, oversight of experiments, and training of certain participants. EJK and JHYP were responsible for conception of the project, oversight of experiments, and training of certain participants, and they drafted the manuscript. All authors read and approved the final manuscript.

\section{Competing interests}

The authors declare that they have no competing interests.

Received: 17 January 2011 Revised: 19 June 2011

Accepted: 11 August 2011 Published: 11 August 2011

\section{References}

1. Jemal A, Siegel R, Xu J, Ward E: Cancer statistics, 2010. CA Cancer J Clin 2010, 60:277-300.

2. Helman S, Harris JR: Diseases of Breast Philadelphia: Lippincott Williams \& Wilkins; 2000.

3. Ali SM, Harvey HA, Lipton A: Metastatic breast cancer: overview of treatment. Clin Orthop Relat Res 2003, 415(Suppl):S132-S137.

4. Thiebaut AC, Kipnis V, Chang SC, Subar AF, Thompson FE, Rosenberg PS, Hollenbeck AR, Leitzmann M, Schatzkin A: Dietary fat and postmenopausal invasive breast cancer in the National Institutes of Health-AARP Diet and Health Study cohort. J Natl Cancer Inst 2007, 99:451-462.

5. Buettner R, Scholmerich J, Bollheimer LC: High-fat diets: modeling the metabolic disorders of human obesity in rodents. Obesity (Silver Spring Md) 2007, 15:798-808.

6. Lin S, Thomas TC, Storlien LH, Huang XF: Development of high fat dietinduced obesity and leptin resistance in $\mathrm{C} 57 \mathrm{BI} / 6 \mathrm{~J}$ mice. Int J Obes Relat Metab Disord 2000, 24:639-646.

7. Carmichael AR: Obesity and prognosis of breast cancer. Obes Rev 2006 , 7:333-340

8. Li Z, Bowerman S, Heber D: Health ramifications of the obesity epidemic. Surg Clin North Am 2005, 85:681-701.

9. Whiteman MK, Hillis SD, Curtis KM, McDonald JA, Wingo PA, Marchbanks PA: Body mass and mortality after breast cancer diagnosis. Cancer Epidemiol Biomarkers Prev 2005, 14:2009-2014.

10. Dawood S, Broglio K, Gonzalez-Angulo AM, Kau SW, Islam R, Hortobagyi GN, Cristofanilli M: Prognostic value of body mass index in locally advanced breast cancer. Clin Cancer Res 2008, 14:1718-1725.

11. Rose DP, Connolly JM, Meschter CL: Effect of dietary fat on human breast cancer growth and lung metastasis in nude mice. J Natl Cancer Inst 1991, 83:1491-1495.

12. Ford CE, Ekstrom EJ, Andersson T: Wnt-5a signaling restores tamoxifen sensitivity in estrogen receptor-negative breast cancer cells. Proc Natl Acad Sci USA 2009, 106:3919-3924.

13. Banka CL, Lund CV, Nguyen MT, Pakchoian AJ, Mueller BM, Eliceiri BP: Estrogen induces lung metastasis through a host compartment-specific response. Cancer Res 2006, 66:3667-3672.

14. Pulaski BA, Ostrand-Rosenberg S: Reduction of established spontaneous mammary carcinoma metastases following immunotherapy with major histocompatibility complex class II and B7.1 cell-based tumor vaccines. Cancer Res 1998, 58:1486-1493.

15. Aslakson CJ, Miller FR: Selective events in the metastatic process defined by analysis of the sequential dissemination of subpopulations of a mouse mammary tumor. Cancer Res 1992, 52:1399-1405.

16. Heppner GH, Miller FR, Shekhar PM: Nontransgenic models of breast cancer. Breast Cancer Res 2000, 2:331-334.

17. Olson LK, Tan Y, Zhao Y, Aupperlee MD, Haslam SZ: Pubertal exposure to high fat diet causes mouse strain-dependent alterations in mammary gland development and estrogen responsiveness. Int J Obesity 2010, 34:1415-1426.

18. Toth LA: Defining the moribund condition as an experimental endpoint for animal research. ILAR J 2000, 41:72-79. 
19. Sauter BV, Martinet O, Zhang WJ, Mandeli J, Woo SL: Adenovirus-mediated gene transfer of endostatin in vivo results in high level of transgene expression and inhibition of tumor growth and metastases. Proc Nat Acad Sci USA 2000, 97:4802-4807.

20. Kim EJ, Shin M, Park H, Hong JE, Shin HK, Kim J, Kwon DY, Park JH: Oral administration of 3,3'-diindolylmethane inhibits lung metastasis of 4T1 murine mammary carcinoma cells in BALB/c mice. J Nutr 2009, 139:2373-2379.

21. Welch DR, Neri A, Nicolson GL: Comparison of 'spontaneous' and 'experimental' metastasis using rat 13762 mammary adenocarcinoma metastatic cell clones. Invasion Metastasis 1983, 3:65-80.

22. Rose DP, Connolly JM: Influence of dietary fat intake on local recurrence and progression of metastases arising from MDA-MB-435 human breast cancer cells in nude mice after excision of the primary tumor. Nutr Cancer 1992, 18:113-122.

23. Kim EJ, Hong JE, Eom SJ, Lee JY, Park JH: Oral administration of benzylisothiocyanate inhibits solid tumor growth and lung metastasis of 4T1 murine mammary carcinoma cells in BALB/c mice. Breast Cancer Res Treat 2011.

24. Cho HJ, Kim WK, Kim EJ, Jung KC, Park S, Lee HS, Tyner AL, Park JH: Conjugated linoleic acid inhibits cell proliferation and ErbB3 signaling in HT-29 human colon cell line. Am J Physiol Gastrointest Liver Physiol 2003, 284:G996-G1005.

25. Denizot F, Lang R: Rapid colorimetric assay for cell growth and survival: modifications of the tetrazolium dye procedure giving improved sensitivity and reliability. J Immunol Methods 1986, 89:271-277.

26. Kwon GT, Cho HJ, Chung WY, Park KK, Moon A, Park JH: Isoliquiritigenin inhibits migration and invasion of prostate cancer cells: possible mediation by decreased JNK/AP-1 signaling. J Nutr Biochem 2009, 20:663-676.

27. Karnoub AE, Weinberg RA: Chemokine networks and breast cancer metastasis. Breast Dis 2006, 26:75-85.

28. McEligot AJ, Largent J, Ziogas A, Peel D, Anton-Culver H: Dietary fat, fiber, vegetable, and micronutrients are associated with overall survival in postmenopausal women diagnosed with breast cancer. Nutr Cancer 2006, 55:132-140.

29. Thomson CA, Thompson PA: Dietary patterns, risk and prognosis of breast cancer. Future Oncol 2009, 5:1257-1269.

30. Xu H, Barnes GT, Yang Q, Tan G, Yang D, Chou CJ, Sole J, Nichols A Ross JS, Tartaglia LA, Chen H: Chronic inflammation in fat plays a crucial role in the development of obesity-related insulin resistance. J Clin Invest 2003, 112:1821-1830

31. Weisberg SP, McCann D, Desai M, Rosenbaum M, Leibel RL, Ferrante AW Jr: Obesity is associated with macrophage accumulation in adipose tissue. $J$ Clin Invest 2003, 112:1796-1808.

32. Zhang $Y$, Proenca R, Maffei M, Barone M, Leopold L, Friedman JM: Positional cloning of the mouse obese gene and its human homologue. Nature 1994, 372:425-432.

33. McGregor GP, Desaga JF, Ehlenz K, Fischer A, Heese F, Hegele A, Lammer C, Peiser C, Lang RE: Radiommunological measurement of leptin in plasma of obese and diabetic human subjects. Endocrinology 1996, 137:1501-1504.

34. Sinha MK, Opentanova I, Ohannesian JP, Kolaczynski JW, Heiman ML, Hale J, Becker GW, Bowsher RR, Stephens TW, Caro JF: Evidence of free and bound leptin in human circulation. Studies in lean and obese subjects and during short-term fasting. J Clin Invest 1996, 98:1277-1282.

35. Garofalo C, Koda M, Cascio S, Sulkowska M, Kanczuga-Koda L, Golaszewska J, Russo A, Sulkowski S, Surmacz E: Increased expression of leptin and the leptin receptor as a marker of breast cancer progression: possible role of obesity-related stimuli. Clin Cancer Res 2006, 12:1447-1453.

36. Hu X, Juneja SC, Maihle NJ, Cleary MP: Leptin: a growth factor in normal and malignant breast cells and for normal mammary gland development. J Natl Cancer Inst 2002, 94:1704-1711.

37. Cleary MP, Phillips FC, Getzin SC, Jacobson TL, Jacobson MK Christensen TA, Juneja SC, Grande JP, Maihle NJ: Genetically obese MMTVTGF-alpha/Lep(ob)Lep(ob) female mice do not develop mammary tumors. Breast Cancer Res Treat 2003, 77:205-215.

38. Albini A, Sporn MB: The tumour microenvironment as a target for chemoprevention. Nat Rev Cancer 2007, 7:139-147.
39. Albini A, Tosetti F, Benelli R, Noonan DM: Tumor inflammatory angiogenesis and its chemoprevention. Cancer Res 2005, 65:10637-10641.

40. Lewis CE, Leek R, Harris A, McGee JO: Cytokine regulation of angiogenesis in breast cancer: the role of tumor-associated macrophages. J Leukoc Biol 1995, 57:747-751.

41. Manabe $Y$, Toda S, Miyazaki K, Sugihara H: Mature adipocytes, but not preadipocytes, promote the growth of breast carcinoma cells in collagen gel matrix culture through cancer-stromal cell interactions. $J$ Pathol 2003, 201:221-228.

42. lyengar P, Combs TP, Shah SJ, Gouon-Evans V, Pollard JW, Albanese C, Flanagan L, Tenniswood MP, Guha C, Lisanti M, Pestell RG, Scherer PE: Adipocyte-secreted factors synergistically promote mammary tumorigenesis through induction of anti-apoptotic transcriptional programs and proto-oncogene stabilization. Oncogene 2003, 22:6408-6423.

43. Walsh C, Tanjoni I, Uryu S, Tomar A, Nam JO, Luo H, Phillips A, Patel N, Kwok C, McMahon G, Stupack DG, Schlaepfer DD: Oral delivery of PND1186 FAK inhibitor decreases tumor growth and spontaneous breast to lung metastasis in pre-clinical models. Cancer Biol Ther 2010, 9:778-790.

44. DuPre SA, Hunter KW: Murine mammary carcinoma 4T1 induces a leukemoid reaction with splenomegaly: association with tumor-derived growth factors. Exp Mol Pathol 2007, 82:12-24.

45. Younos I, Donkor M, Hoke T, Dafferner A, Samson H, Westphal S, Talmadge J: Tumor- and organ-dependent infiltration by myeloidderived suppressor cells. Int Immunopharmacol 2011, 11:816-826.

46. Tao K, Fang M, Alroy J, Sahagian GG: Imagable 4T1 model for the study of late stage breast cancer. BMC Cancer 2008, 8:228.

\section{doi:10.1186/bcr2927}

Cite this article as: Kim et al:: Dietary fat increases solid tumor growth and metastasis of 4T1 murine mammary carcinoma cells and mortality in obesity-resistant BALB/c mice. Breast Cancer Research 2011 13:R78.

\section{Submit your next manuscript to BioMed Central and take full advantage of:}

- Convenient online submission

- Thorough peer review

- No space constraints or color figure charges

- Immediate publication on acceptance

- Inclusion in PubMed, CAS, Scopus and Google Scholar

- Research which is freely available for redistribution

Submit your manuscript at www.biomedcentral.com/submit
C) Biomed Central 